\title{
A Pilot Study on Predictive Factors for Over Weight and Obesity in School Children of Coimbatore, Tamil Nadu, South India
}

\author{
S.Shajithanoop ${ }^{1}$, C.Palanivelư ${ }^{2}$, P.Senthilnathan ${ }^{2}$, P.Praveenraj ${ }^{2}$ and M.V.Usha Rani ${ }^{1}$ \\ ${ }^{1}$ Department of Environmental Sciences, Bharathiar University, Coimbatore- 641046, Tamil Nadu, India \\ ${ }^{2} \mathrm{Gem}$ Hospital and Research centre, Coimbatore-641045, Tamil Nadu, India
}

\begin{abstract}
Objective: To understand specific factors associated with overweight and obesity in children of Coimbatore through a non invasive method.

Methodology: A cross - sectional study was conducted in four urban schools of Coimbatore and school children aged between 9 years and 17 years of age $(n=252$, mean age $13 \pm 2.3$ years, Boys $n=142$, Girls $n=111$ ) were recruited by purposive random sampling method. Children with physical limitations, mental disability or children undergoing any form of clinical therapy were not included in this study. Anthropometric assessment was done and data were analysed by Linear and Logistic regression models using SPSS (version 11, Chicago: SPSS, Inc.) P value less than 0.05 was considered as statistically significant.

Results: The mean BMI in boys $\left(16.7 \pm 2.8 \mathrm{~kg} / \mathrm{m}^{2}\right)$ was lower than the mean BMI of girls $\left(19.1 \pm 3.3 \mathrm{~kg} / \mathrm{m}^{2}\right)$. The mean BMI and body weight in obese girls with "double chin" was $23.9 \pm 2.6 \mathrm{~kg} / \mathrm{m}^{2}$ and $56.8 \mathrm{~kg}$ respectively. Importantly, the mean body weight $(49.4 \mathrm{~kg})$ was higher in girls of parents with hypertension, followed by the mean body weight of girls $(44.6 \mathrm{~kg})$ of obese parents. Specific factors namely outdoor physical activity as playtime, dietary pattern were associated significantly with BMI ( $<<0.01$, $\left.r^{2}=0.81\right)$ in the children of this study. The BMI of children with 'double chin' was comparatively high than children without double chin. Sedentary children who habitually consume snacks while watching television are at a higher risk (Odds ratios=1.44, $\mathrm{p}<0.01$,) for obesity than children who do not. Progressive increase in frequency and duration of outdoor playtime significantly (Odds ratios: $2.54, \mathrm{p}<0.01$ ) reduces excess weight in overweight and obese children by nearly three times than those children who do not play.
\end{abstract}

Keywords: Childhood obesity; Physical activity; Predictive factors; Prevention; Odds ratios

\section{Introduction}

Obesity is a global public health crisis as around $10 \%$ of children worldwide are overweight and $25 \%$ are obese [1,2]. In India, the prevalence of overweight and obesity ranges between $9 \%$ to $27 \%$ and $1 \%$ to $12.9 \%$ respectively [3-9]. Childhood obesity leads to Type 2 diabetes, gallbladder disease and osteoarthritis in adulthood [10]. The upsurge in rates of childhood obesity can be attributed due to changing lifestyle, urbanized food patterns, increased access to " fast foods" and decrease in physical activity [11]. Weight increases with age and the risk of an overweight child becoming an obese adult is two times higher than a non obese child $[12,13]$. Overweight adolescents are 18 times more likely to be obese in adulthood than lean adolescents [14]. Further, obese and overweight adolescents are at higher risk of developing hypertension in adulthood [15]. There are numerous factors associated with obesity in children and it varies between each section of population of a country. Coimbatore city is located in Tamil Nadu state of Southern India contributing the highest GDP (Gross domestic product) among other districts of Tamil Nadu. The district is located in the North West part of the State at 10o 12' and 11o 57' Latitude and between 76o 39' and 77o 56 Longitude. The district has an area of 7469 sq. kilometers. It is popularly known as 'Manchester of South India' because of its heavy concentration of Textiles industries [16]. Several studies have evaluated the prevalence of obesity in children of India but only a few of them have revealed certain predictive factors that predispose children to obesity with reference to the area of study. Hence, this study was aimed to elucidate the factors that are associated with overweight and obesity and suggest measures which would reduce weight gain and obesity in urban school children of Coimbatore.

\section{Methodology}

The study protocol was reviewed and approved by the ethics committee of a multi-specialty hospital in Coimbatore. A list of urban schools with total number of school children in each was obtained and four urban schools were randomly selected. The sample size was calculated to represent $10 \%$ of the total number of urban school children ( $n=2600$ ) for which purposive random sampling method was adopted to recruit 260 urban school children of Coimbatore. The objectives of the study were explained in detail to the parents and teachers of the children and written consents were obtained. A customized questionnaire incorporating questions on snacking habits, physical activity, class room time, preference for games etc was designed and validated in 50 children randomly selected from the schools chosen for the study. The pre-validated questionnaire was explained in detail to all the children two days prior to the actual date of the study and queries from children were duly answered by the research team to ensure no conflicting responses. Children with physical limitations, mental disability or children undergoing any form of clinical therapy were not included in this study. Out of 260 participants, eight children opted out of the study and a total of 252 consenting children aged between $9-17$ years of age (mean age $13 \pm 2.3$ years, Boys $n=142$, girls $n=111$ ) from four different urban schools of academic excellence were enrolled. The same questionnaire was used for children of all schools under study

*Corresponding author: M.V. Usha Rani, Department of Environmental Sciences, Bharathiar University, Coimbatore- 641046, Tamil Nadu, India, E-mail: malla_drur@yahoo.com

Received July 24, 2013; Accepted September 24, 2013; Published September 27, 2013

Citation: Shajithanoop S, Palanivelu C, Senthilnathan P, Praveenraj P, Usha Ran M.V (2013) A Pilot Study on Predictive Factors for Over Weight and Obesity in School Children of Coimbatore, Tamil Nadu, South India. J Nutr Disorders Ther 3 : 128. doi:10.4172/2161-0509.1000128

Copyright: (C) 2013 Shajithanoop S, et al. This is an open-access article distributed under the terms of the Creative Commons Attribution License, which permits unrestricted use, distribution, and reproduction in any medium, provided the original author and source are credited. 
and the first working day of the week was chosen for the study. The children were instructed to answer the self-administered questionnaire that contained 36 multiple choice questions. It approximately required eight minutes for each participant to record details such as snacking habits at school, physical activity as playtime per week and per day, duration of class room hours, academic objectives, known health status of parents, favorite snack item consumed frequently. Dietary habits were categorized mainly as vegetarian and non-vegetarian based on the responses to the questionnaire. Other details such as occupation of parents, mode of transport to school, leisure activities of parents, mode of recreation for the family, family size, number of siblings were also recorded and cross-checked during face-to-face interview between researchers and parents of all the participating children. The completed questionnaires were checked for lapses, if any, coded and recorded in a confidential data base. The students were instructed to report to the clinic in light clothes the next day. Body Mass Index (BMI) was recorded for each participant in accordance to the standard guidelines [17] by male and female nurses for the subjects of respective genders. The weight of each participant was recorded in kilograms $(\mathrm{kg})$ using a calibrated electronic weighing machine. The height was recorded in centimeters $(\mathrm{cm})$ using a stadiometer fixed to the wall. The BMI was calculated by dividing weight (in $\mathrm{kg}$ ) with height in meter squared $\left(\mathrm{m}^{2}\right)$ and expressed as $\mathrm{kg} / \mathrm{m}^{2}$. Clinical examination for phenotypic features namely "Acanthosis nigricans, "double chin" \& "buffalo hump" was also conducted for each participant by visual observation of the neck and chin under optimum lighting. The detailed definition of these terms is given elsewhere [18]. The phenotypic examination was repeated twice for concordance and the clinical history of the children was obtained with parental consent for confounding factors such as hormonal imbalance, and metabolic disorders predisposing to obesity. This was cross-checked with the medical record of each student maintained in the school by a certified medical doctor. The data obtained were coded and statistical analyzed by ANOVA, Pearson's correlation test, linear regression analysis and Logistic regression analysis were performed using SPSS (version 11, Chicago: SPSS, Inc.) Statistical significance was inferred as $P$ value less than or equal to 0.05 .

\section{Results}

The mean BMI in boys $\left(16.7 \pm 2.8 \mathrm{~kg} / \mathrm{m}^{2}\right)$ was lower than the mean BMI of girls $\left(19.1 \pm 3.3 \mathrm{~kg} / \mathrm{m}^{2}\right)$. The mean BMI and body weight in obese girls with double chin was $23.9 \pm 2.6 \mathrm{~kg} / \mathrm{m}^{2}$ and $56.8 \mathrm{~kg}$ respectively. Most of the study participants $(\mathrm{n}=214)$ who reported their dietary habit as non -vegetarians had higher mean body mass ( $40.8 \mathrm{~kg}$ ) than vegetarians $(37.4 \mathrm{~kg})$. Among non-vegetarians, the mean body weight $(45.2 \mathrm{~kg})$ was highest in participants who consumed chicken as the only form of cooked meat and the lowest body weight $(34.1 \mathrm{~kg})$ was recorded in subjects who consumed only eggs and not meat in any form. A significant positive correlation was observed between BMI and variables such as age, gender, snacking habits $(\mathrm{P}<0.05)$. A negative correlation was observed between BMI and the increase in physical activity. Parental history of any one of the following disorders namely Type 2 Diabetes, obesity, hypertension and arthritis indicated a positive correlation with the body weight of the participants. "Buffalo hump" and "Acanthosis nigricans "were absent in the study participants but female children with "double chin" had the highest BMI $(23.9 \pm 3.8 \mathrm{~kg} /$ $\left.\mathrm{m}^{2}\right)$. Importantly, the mean body weight $(49.4 \mathrm{~kg})$ was higher in girls who had hypertensive parents followed by the mean body weight of girls $(44.6 \mathrm{~kg})$ of obese parents. In boys, the highest mean body weight $(42.5 \mathrm{~kg})$ was observed for those whose parents were obese. The class room time for each participating student was 6 hours per day. Linear regression analysis model indicated that variables namely outdoor physical activity as playtime, dietary pattern, height and weight were significant factors $\left(\mathrm{p}<0.01, \mathrm{r}^{2}=0.81\right)$ influencing $\mathrm{BMI}$ in the present study (Table 1). Additionally, logistic regression analysis of the data revealed that four important factors namely "attending special classes, "snack consumption while watching television", "frequency of outdoor games per week" and "duration of play time" having significant influence on BMI. Sedentary children who habitually consume snacks while watching television are at a higher risk $(\mathrm{p}<0.01$, Odds ratios: 1.4$)$ for obesity than children who do not consume snacks while watching television. On the contrary, we observed that children who played games are at lower risks of developing obesity (Odds ratios: $2.54, \mathrm{p}<$ 0.01 ,) (Table 2) than children who do not play games. In this study, we observed that boys preferred cricket and girls preferred indoor games as a form of physical activity.

\section{Discussion}

The present study has adopted a noninvasive clinical approach and identified four factors that determine obesity in urban school children of Coimbatore, South India. Further, no other study from Coimbatore has observed for "double chin" as a phenotypic marker in childhood obesity studies. This study has made important observations wherein, the female participants were obese and overweight but boys were of normal weight. Most importantly, we observed that female children of hypertensive parents had higher BMI than female children of normotensive obese parents. This needs to be investigated in detail for clinical implications in obesity. There were no significant differences in height between male and female children of the study cohort. Double Chin" is a phenotypic marker of metabolic syndrome and observed that the BMI of children with "double chin" was comparatively high

\begin{tabular}{|c|c|c|c|c|c|}
\hline \multirow{2}{*}{ Significant Variables } & Unstandardised coefficient & Standardised Coefficients & $t$ value & P Value & Regression coefficient $\left(r^{2}\right)$ \\
\cline { 2 - 5 } & Beta value & Beta value & & & \\
\hline Dietary pattern & 15.098 & - & 13.047 & 0.00 \\
\hline Frequency of playing outdoor games in a week & -0.338 & -0.079 & -2.075 & 0.00 \\
\hline Weight & 0.284 & 0.995 & 22.450 & 0.00 & \multirow{2}{*}{$\mathbf{0 . 8 1}$} \\
\hline Height & -0.057 & -0.280 & -6.465 & 0.00 & \\
\hline
\end{tabular}

Table 1: Coefficient values of Regression model for BMI.

\begin{tabular}{|l|c|c|c|c|}
\hline \multicolumn{1}{|c|}{ Significant variables } & $\boldsymbol{\beta}$ coefficient values & Standard error & P value & 0.01 \\
\hline Attending special classes at school & 0.662 & 0.014 & 0.00 & 2.89 \\
\hline Frequency of playing games & -0.616 & 0.008 & 0.00 & 1.00 \\
\hline Duration of playing games & -0.935 & 0.009 & 0.00 & 2.54 \\
\hline Eating snacks while watching TV & 0.365 & 0.010 & 1.44 \\
\hline
\end{tabular}

Table 2: Logistic regression model with $\beta$ Coefficient values and odds Ratios. 
Citation: Shajithanoop S, Palanivelu C, Senthilnathan P, Praveenraj P, Usha Rani M.V (2013) A Pilot Study on Predictive Factors for Over Weight and Obesity in School Children of Coimbatore, Tamil Nadu, South India. J Nutr Disorders Ther 3: 128. doi:10.4172/2161-0509.1000128

Page 3 of 4

than children without double chin." It can be stated that subjects with "double chin" are at higher risk of developing metabolic syndrome [18] if appropriate interventions are not initiated. Physical activity is an important factor affecting BMI. It was observed that physical activity through sports and games decreased as the children progressed to higher classes due to increasing academic goals. Furthermore we observed that children of classes eight to twelve (aged between 11 to 15 years) tend to skip physical education classes at school to avail extra study time. This can be attributed to high academic competition from peers and parental expectations of higher grades from their children. Specifically, girls preferred playing indoor computer games or watching games on television. On the other hand, boys preferred playing cricket only if they had sufficient number of playmates for a team. This factor could lead to the decline in independent playtime and also optimal physical activity. Less physical inactivity at home and at school together pose an elevated risk for obesity and metabolic syndrome in the later years, if appropriate interventions are not adopted. Snacking habit of children was influenced by the social status of parents. In this study, we also observed that children preferred urban food pattern than traditional foods, which were home - made and nutritious. Children with two earning parents visited eateries more often than children with a single earning parent. Similar observations were recorded in a study by Vohra et al. who identified paternal education and income as determinants of obesity in schoolchildren of Lucknow, India [19]. Saker et al. reported parental income and education as a determinant of obesity in children of western Algeria [20]. In this study we observed that children of parents with high income increased access to expensive, calorie dense "fast food'. Parents with higher income status accompany their children to large fast food outlets for leisure during weekends. On weekdays parents claim lack of time as a reason for not providing traditional, homemade snack items. Furthermore, such parents of children did not object strongly to children preferring snack items such as pizzas and burgers. In due course, children imbibe the habit of indiscriminate consumption of fast foods, which leads to obesity. The predominant form of recreational activity for the children was watching television. In the present study, we report that consumption of calorie dense snacks by children while watching television increases the risk of obesity by nearly three times. This could also be an intrinsic factor leading to decreased physical activity of children at home. Horn et al. reported that the risk of developing obesity increases with increase in duration of time spent in television viewing [21]. Another study from South India reported significant association between sleep duration, television viewing and overweight in urban children. Children who viewed television or more than 1.5 hours a day were at higher risk for developing obesity, than children who viewed television for less than one hour daily [22]. In our study, the mean television viewing time was 45 minutes per day and also has included snacking habit of children during television viewing, as an important determinant which increases the risk of obesity up to 1.4 times than children who do not consume snacks while watching television.

We also observed that school children of the study cohort lacked awareness on the ill- effects of obesity on human health. The participating students lacked awareness on terms such as "BMI", waist circumference, ideal weight for a specific age, and adiposity. These children had not participated in any form of health awareness programs either at school or elsewhere. The importance of sustained health education and intervention is well understood from the results of study by Yannis et al. recorded significant increase in physical activity in children and their parents [23]. Kuh and Cooper reported that sustained physical activity needs to be initiated in childhood and adolescence [24]. It can be stated that the role of parental motivation plays a vital role in initiating physical activity in children. In the present study, we noted that parents encouraged their children to participate in sports and outdoor games only when their children were in lower classes. The degree of physical activity and exercise decline yearly as the children progressed to higher classes. This is because the children had to spend more time at school and for coaching classes in the evenings to meet academic objectives. Parents need to be advised on the importance of physical exercise for children in their growing years as the linear growth in children as height decreases when physical activity declines. This is a pilot study, which has identified predictive factors of obesity in urban school children and does estimate the prevalence of obesity in the study area. Clinical analysis of the study subjects for body fat percentage, metabolic syndrome and insulin resistance needs to be done a clinical setting. The observations of the pilot study need to be extended to a larger cohort in rural areas to derive significant implications Longitudinal, cross sectional studies between several institutions are required to estimate the prevalence of obesity and metabolic syndrome in children and adolescents of Coimbatore.

\section{Conclusion}

There is evidence of rapid changes in dietary pattern in adults and children when they shift from rural to urban areas [25]. Children of today consume food more often in commercial food centers without an understanding of the nutritional imbalance that energy dense food can impose. The role of parental motivation and participation in physical activity programs assumes paramount significance. Parents and children need to be constantly educated in making nutritious food choices and the health burden that India faces due to Type 2 diabetes. Effective public health programs need to be advocated in each school to combat the rising epidemic of childhood obesity. It will be ideal to include educative programs on childhood obesity as a part of the curriculum that the schools currently adopt.

\section{Acknowledgement}

The authors are thankful to the parents and children who participated in this study. Administrative assistance offered by the school authorities and GEM hospital, Coimbatore is gratefully acknowledged

\section{References}

1. Waxman A (2003) WHO: Global Strategy on Diet, Physical activity and Health Geneva, Switzerland. Food Nutr Bull 24: 281-4.

2. Dietz WH, Robinson TN (2005) Clinical practice. Overweight children and adolescents. N Eng J Med 2005 19: 2100-2109.

3. Ramachandran A, Snehalatha C, Vinitha R, Thayyil M, Kumar CK, et al. (2002) Prevalence of overweight in urban Indian adolescent school children. Diab Res Clin Prac 57: 185-90.

4. Kapil U, Singh P, Pathak P, Dwivedi SN, Bhasin S (2002) Prevalence of obesity among affluent adolescent school children in Delhi. Indian Pediatr 39: 449-452.

5. Sidhu S, Kaur N, Kaur R (2006) Overweight and obesity in affluent school children of Punjab. Ann Hum Biol 33: 255-9.

6. Chatwal J, Verma M, Rair SK (2004) Obesity among pre-adolescent and adolescents of a developing country (India). Asia Pac J Clin Nutr 13: 231-235

7. Marwaha RK, Tandon N, Singh Y, Agarwal R, Mani K (2006) A study of growth parameters and prevalence of overweight and obesity in school children from Delhi. Indian Pediatr 43: 943-952.

8. Bose K, Bisai S, Mukhopadhyay A, Bhadra M (2007) Overweight and obesity among affluent Bengalee school girls of Lake Town, Kolkata, India. Matern Child Nutr 3: 141-145.

9. Sidhu S, Marwah G, Prabhjot (2005) Prevalence of overweight and obesity among affluent adolescent school children of Amritsar, Punjab. Coll Anthropol 
Citation: Shajithanoop S, Palanivelu C, Senthilnathan P, Praveenraj P, Usha Rani M.V (2013) A Pilot Study on Predictive Factors for Over Weight and Obesity in School Children of Coimbatore, Tamil Nadu, South India. J Nutr Disorders Ther 3: 128. doi:10.4172/2161-0509.1000128

\section{9: 53-59.}

10. (2000) Obesity: Preventing and managing the global epidemic. Report of a WHO consultation 894: 1- 253.

11. Singh M, Sharma M (2005) Risk factor for obesity in children. Indian Pediat 42: $183-185$

12. Ogden CL, Flegal KM, Caroll MD, Johnson CL (2002) Prevalence and trends in overweight among US children and adolescents 1999- 2000. JAMA 288 1728-1732.

13. Serdula MK, Ivery D, Coates RJ, Freedman DS, Williamson DF, et al. (1993) Do obese children become obese adults? A review of the literature. Prev Med 22: $167-177$

14. Whitaker RC, Wright JA, Pepe MS, Seidel KD, Dietz WH (1997) Predicting obesity in young adulthood from childhood and parental obesity. N Engl J med 337: 869-873.

15. Field AE, Cook NR, Gillman MW (2005) Weight status in childhood as a predictor of becoming overweight or hypertensive in early adulthood. Obes res 13: 163-169.

16. "Pradan Mantiri Gram Sadak Yojana”.

17. Cole TJ, Bellizzi MC, Flegal KM, Dietz WH (2000) Establishing a standard definition for child overweight and obesity worldwide: International survey. BMJ 320: $1240-1243$.

18. Misra A, Jaiswal A, Shakti D, Wasir J, Vikram NK et al. (2008) Novel phenotypic markers and screening score for the metabolic syndrome in adult Asian Indians. Diabetes Res Clin Pract 79: e1-5.

19. Vohra R, Bharadwaj P, Srivastava JP, Srivastava S, Vohra A (2011) Overweight and obesity among school going children of Lucknow city. $\mathrm{J}$ of family \& Comm Med 18: 59-62.

20. Saker M, Merzouk H, Sid AM, Samira BA, Michel N (2011) Predictive factors of obesity and their relationships to dietary intake in school children in western Algeria. Maedica (Buchar) 6: 90-99

21. Horn OK, Paradis G, Potvin L, Macaulay AC, Serge D (2001) Correlates and predictors of adiposity among Mohawk children. Preventive Med 33: $274-281$.

22. Rebecca K, Bhat S, Thomas T, Vaz M, Kurpad AV (2007) Television viewing and sleep are associated with overweight among urban and semi urban South Indian children. Nutr J 6: 1-4

23. Yannis M, Anthony K, George M (1998) The effects of health education intervention initiated at first grade over a 3 year period: physical activity and fitness indices. Health educres 13: 593-606.

24. Kuh DJ, Cooper C (1992) Physical activity at 36 years: Patterns and childhood predictors in a longitudinal study. J Epidemiol \& Comm Health 46: 114-119.

25. Shetty PS (2002) Nutrition transition in India. Public health Nutr 5: 175-182. 